高出力 CW ファイバレーザ技術

\title{
High Power Continuous Wave Fiber Laser Technologies
}

金 田 恵 司*

Keiji KANEDA

Key Words: High Power Fiber Laser, Stimulated Raman Scattering, Reflection Resistance, Metal Processing

\section{1. まえがき}

波長約 $1 \mu \mathrm{m}$ の近赤外領域で発振するイッテルビウム $(\mathrm{Yb})$

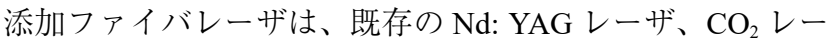
ザなどに比べてビーム品質や電力効率、信頼性など多くの 面で優れており、切断、溶接、マーキングおよびスクライ ビングなどの材料加工分野での普及が急速に進んでいる。

当社は光通信分野において、増幅用ファイバなどの特殊 ファイバ技術、ファイバ・ブラッグ・グレーティング (FBG) や励起コンバイナなどの光部品技術、各光部品や光ファイ バを接続する光ファイバ接続技術をつちかってきた。近年 は高出力半導体レーザ (LD) を自社の要素技術に加え、ファ イバレーザに必要な全ての技術を保有するに至っている。

本稿では、当社の純国産高出力ファイバレーザの特長、 機能、製品ラインアップについて述べる。

\section{2. ファイバレーザの構成}

2.1 ファイバレーザ共振器の基本構成

Fig.1 に希土類添加コア高出力ファイバレーザの基本構 成を示す。複数の励起 LD 光は、励起コンバイナを介し増 幅用ファイバに導入され、コア中の活性元素の電子を励起

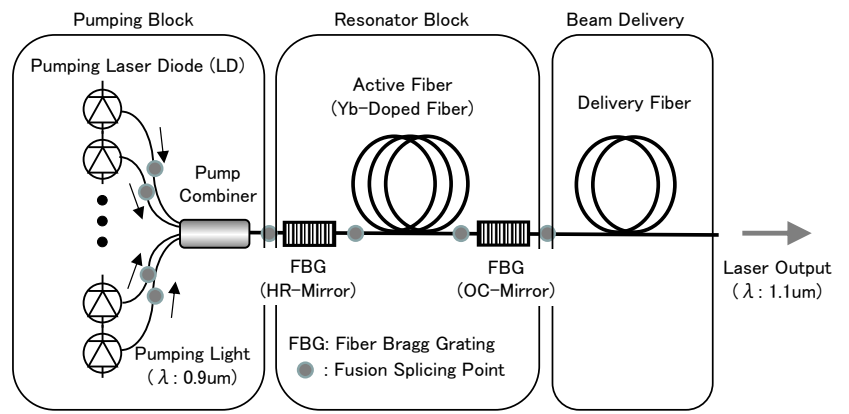

Fig.1 Fundamental Fiber Laser Optical Circuit.
波長に応じたエネルギー準位に励起する。励起された電子 が基底準位に遷移する際、両準位間のエネルギー差に応じ た波長の光を自然放出（発光）する。

増幅用ファイバの両側には光ファイバのコアに回折格子 を形成した FBG がある。FBG は、特定波長を反射するミ ラーとして働き、片側を高反射率、もう片側を低反射率と することでレーザ共振器を構成する。この共振器中で、自 然放出光のうち FBG で選択的に反射された特定波長成分の 光を種として光の誘導放出が起こる。誘導放出された光は、 共振器内部を伝搬し両 FBG で反射される。この間誘導放出 が繰り返されることでレーザ光が生成され、低反射率側の FBG 出口より出射される。

2.2 高出力ファイバレーザの構成

当社の $8 \mathrm{~kW}$ ファイバレーザの構成を Fig.2 に示す。6 台 のファイバレーザユニットからの出力光を出力結合器で結 合することにより、8 kW 出力を実現している。各ファイ バレーザユニットは横モードシングルでレーザ発振してお り、それぞれ $1.4 \mathrm{~kW}$ を出力する。

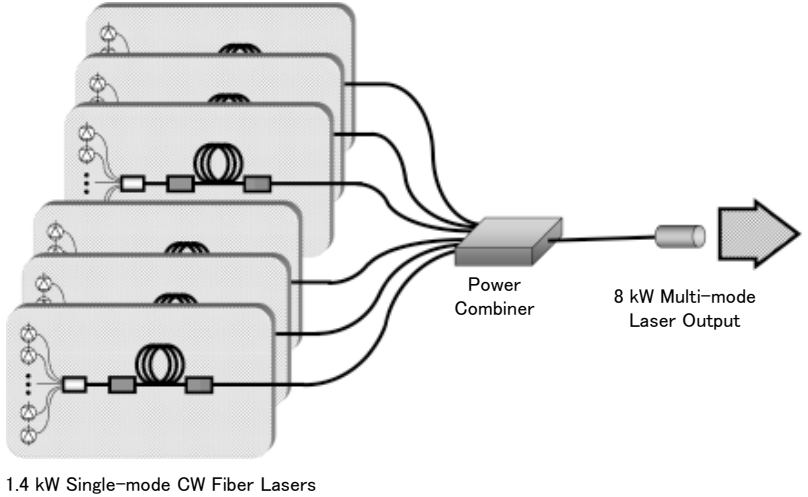

Fig.2 Schematic of 8 kW Multi-mode Fiber Laser.

*株式会社フジクラエネルギー・情報通信カンパニーファイバレーザ事業部（～285-8550 千葉県佐倉市六崎 1440） Fiber Laser Division, Power \& Telecommunication Systems Company (1440 Mutsuzaki, Sakura-shi, Chiba 285-8550 Japan) 


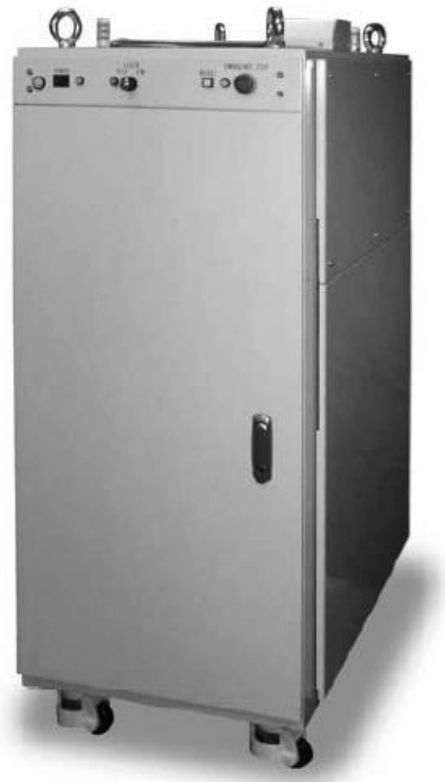

Fig.3 8 kW CW Fiber Laser.

Table 1 Specification of $8 \mathrm{~kW}$ CW Fiber Laser.

\begin{tabular}{|l|l|}
\hline Items & Spec. Values \\
\hline Center Wavelength & $1070 \mathrm{~nm}$ (Typ.) \\
\hline Rated Power & $8 \mathrm{~kW}$ \\
\hline BPP & $\leqq 4.5 \mathrm{~mm} \cdot \mathrm{mrad}(3.0 \mathrm{~mm} \cdot \mathrm{mrad}$, Typ.) \\
\hline Feed Fiber Core dia. & $100 \mu \mathrm{m}$ \\
\hline Output Stability & $< \pm 2 \%$ \\
\hline Max. modulation freq. & $10 \mathrm{kHz}$ \\
\hline Power Supply & Three-phase $200 \mathrm{~V}(50 / 60 \mathrm{~Hz})$ \\
\hline Cooling & Water \\
\hline Dimension & $690 \mathrm{~W} \times 1200 \mathrm{D} \times 1570 \mathrm{H}$ in $\mathrm{mm}$ \\
\hline
\end{tabular}

出力結合器は、低い伝搬損失と高度な耐光パワー性能が 求められる。われわれの出力結合器は光部品技術を活用し た独自構造を採用することにより結合損失 $3 \%$ 以下を達成 しており、8 kW 出力に耐え得る高い信頼性を備えている。

Fig.3に $8 \mathrm{~kW}$ ファイバレーザの外観を、Table 1 に主要 諸元を示す。本製品はコア径 $100 \mu \mathrm{m}$ のフィードファイバ から波長 $1070 \mathrm{~nm}$ で $8 \mathrm{~kW}$ のレーザ光を出力する。出力光 のビームパラメータ積 (BPP) は $4.5 \mathrm{~mm} \cdot \mathrm{mrad}$ (典型值 : 3.0 $\mathrm{mm} \cdot \mathrm{mrad})$ であり、十分な加工性能を有している。本体キャ ビネットはIP54 相当の防塵・防水構造となっており、様々 な設置環境に対応する。

Fig.4にファイバレーザの出力特性を示す。ファイバレー ザ装置全体での変換効率（ウォールプラグ効率）は $38 \%$ であり、従来の固体レーザと比較して省電力性能に優れて いる。

また励起 LD を複数個搭載し圥長性をもって駆動するこ とにより、励起 LD 出力が低下してきた場合においても、

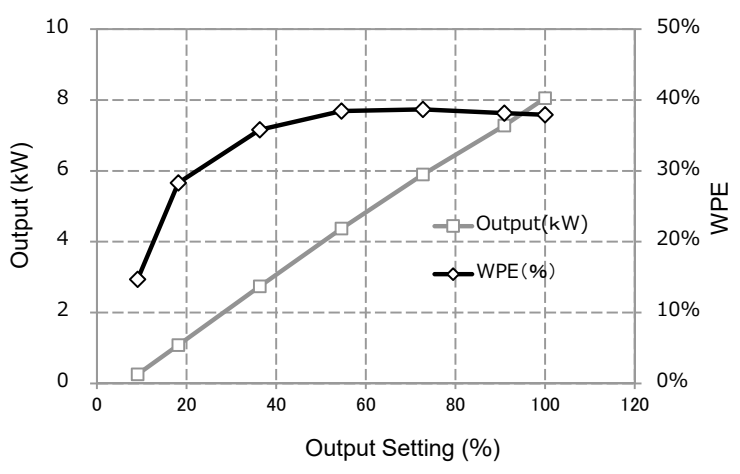

Fig.4 Characteristics of 8 kW CW Fiber Laser.

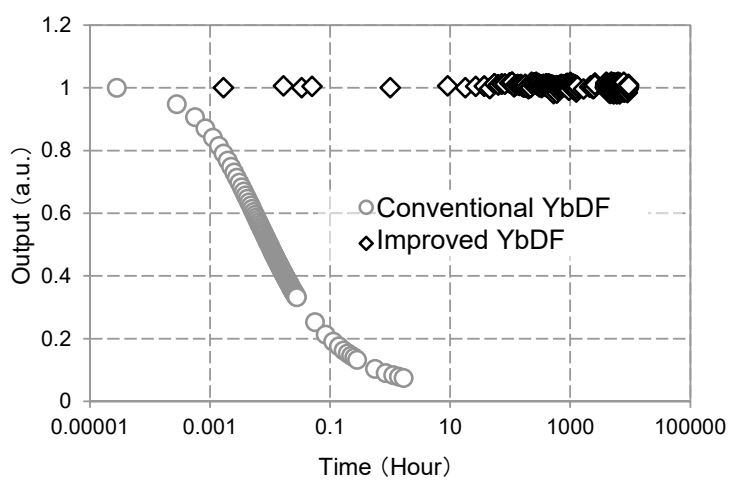

Fig.5 Characteristics of Photo-Darkening Suppressed Yb-Doped Fiber.

駆動電流を増加させることで、継続して得られるよう長寿 命設計されている。

\section{3. ファイバレーザの高出力化技術}

\section{1 フォトダークニングの抑制}

ファイバレーザでは、高強度の励起光とレーザ光が共存 する $\mathrm{Yb}$ 添加光増幅用ファイバ $(\mathrm{YbDF})$ において、光ファイ バ損失が増加するいわゆるフォトダークニングが問題とな る。レーザ出力劣化を抑えるため、フォトダークニングの 抑制は高出力ファイバレーザに必須の技術である。

従来の YbDF は短時間のうちにフォトダークニングに よって本来の $10 \%$ 以下まで出力が低下してしまうが、当 社が独自技術で開発したフォトダークニング抑制 YbDFに は出力劣化が見られないことがわかる (Fig.5)。当社のす ベてのファイバレーザ製品にはこのフォトダークニング抑 制技術が採用されている。

3.2 誘導ラマン散乱 (Stimulated Raman Scattering: SRS) 光の 抑制

ファイバレーザはその構造上、加工物からの反射光に対 する耐性が弱いことが以前から指摘されている。

反射光耐性を妨げる大きな要因として、ファイバ内で発 生する誘導ラマン光があげられる。高出力ファイバレーザ 


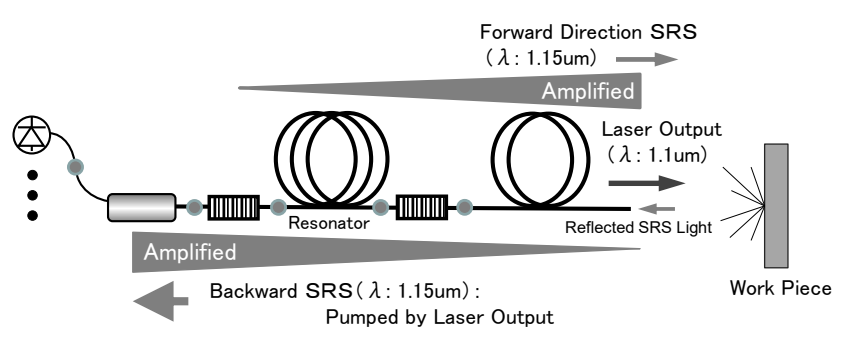

Fig.6 Generation of SRS in Fiber Laser.
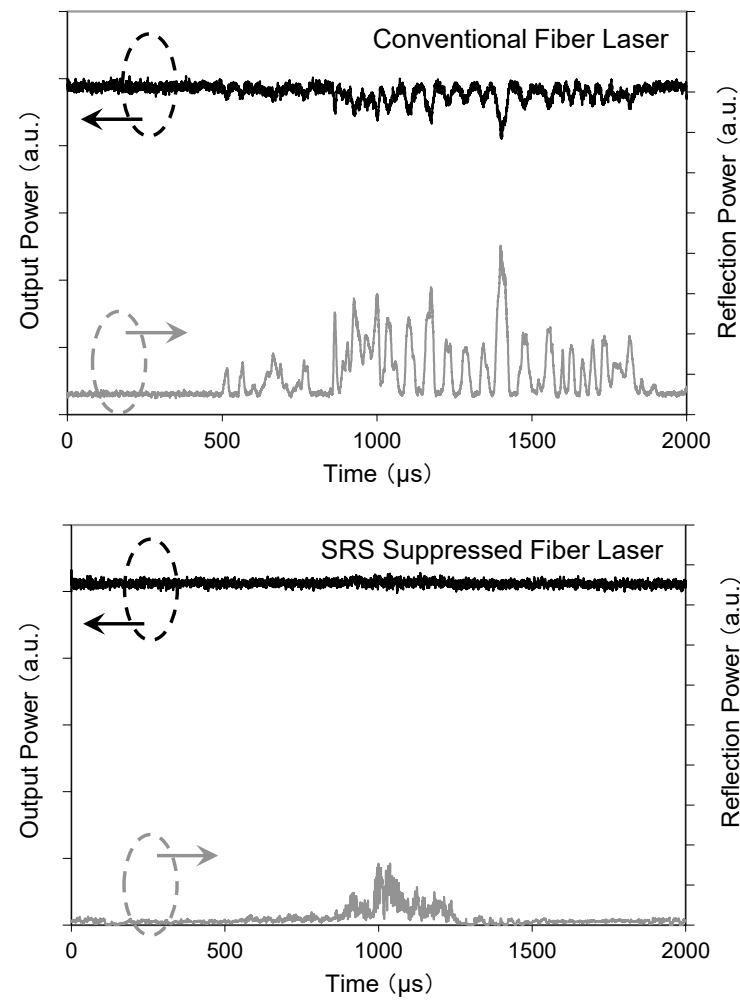

Fig.7 Time variation of Output/Reflection Power.

では、出力光に非線形光学現象の一つであるの誘導ラマン 散乱 (SRS) 光が含まれる。出力光に含まれる SRS 光が加工 物で反射しファイバレーザ内に戻った場合、ファイバを逆 方向に伝播しながらラマン増幅される。この際、出力光は 反射 SRS の励起光となり、SRS 光の増幅に伴い減少する (Fig.6)。結果、レーザ出力は不安定となり、また増幅され た SRS 光は高反射 FBG を突き抜けて光部品や励起 LDに 到達し、最悪の場合機器を故障に至らしめる。

特に銅やアルミなどの高反射材料の加工では、加工ヘッ ドを傾けるなどにより、反射光がファイバレーザ内に戻ら ないようにして加工せざるを得なかった。加工の自由度を 上げるためにも、ファイバレーザの加工物からの反射光耐 性を高めることが重要である。
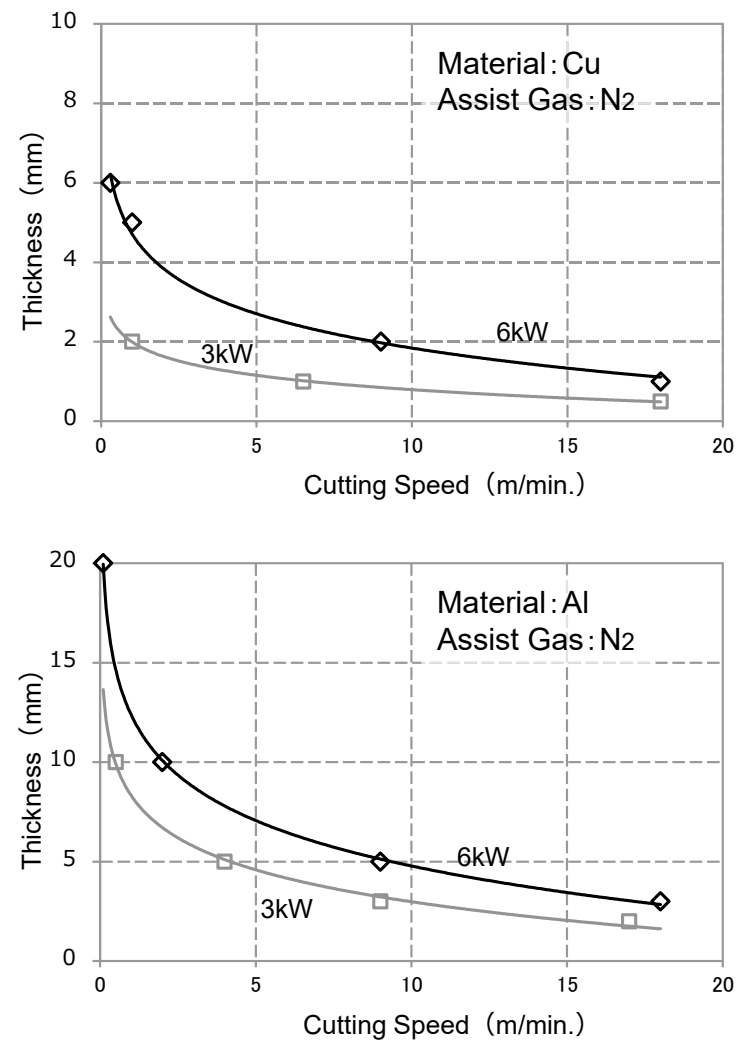

Fig.8 Cutting Performance.

われわれは光ファイバの構造パラメータを最適化し、 SRS 光の発生を抑制し、安定したレーザ出力特性を実現し た。Fig.7にファイバレーザ内部に戻った反射光レベルお よびレーザ出力光レベルの時間変化を示す。SRS の発生を 抑制していないファイバレーザでは、加工物から反射光が 戻ると同時にレーザ出力も変動しているのに対し、SRS の 発生を抑制したファイバレーザの出力光レベルは、反射光 が戻った場合でもその影響を受けずに安定して動作してい ることがわかる。この技術により、当社のファイバレーザ は加工ヘッドを垂直に設置しても、加工物からの反射にほ とんど影響されず、安定した加工を提供することができる。

\section{4. 加工事例}

Fig.8に当社製高出力ファイバレーザを用いて行った銅、 アルミの窒素䨌囲気下における切断実験の結果を示す。

加工ヘッドは対象物に対して垂直に設置し実験を行った が、当社製ファイバレーザの高い反射光耐性により、高反 射材料に対する切断加工も加工へッドを傾けることなく実 現することができた。これらは一例であり、今後も高出力 と高反射耐性を兼ね備えた、当社の高出力ファイバレーザ を用いて加工技術検討を行うことにより、加工速度の向上、 切断加工板厚の増加、適応材料の拡大などが期待できる。 